\title{
The Future of PSMA-Targeted Radionuclide Therapy: An Overview of Recent Preclinical Research
}

\author{
Eline A.M. Ruigrok ${ }^{1,2, *}$, Wytske M. van Weerden ${ }^{2}\left(\mathbb{D}\right.$, Julie Nonnekens ${ }^{1,3,4,+}$ and \\ Marion de Jong ${ }^{1,+}$ \\ 1 Dept. of Radiology and Nuclear Medicine, Erasmus MC, 3015 GD Rotterdam, The Netherlands \\ 2 Dept. of Experimental Urology, Erasmus MC, 3015 GD Rotterdam, The Netherlands \\ 3 Dept. of Molecular Genetics, Erasmus MC, 3015 GD Rotterdam, The Netherlands \\ 4 Oncode Institute, Erasmus MC, 3015 GD Rotterdam, The Netherlands \\ * Correspondence: e.ruigrok@erasmusmc.nl; Tel.: +31-10-704-4971 \\ + Authors equally contributed to the work.
}

Received: 27 September 2019; Accepted: 24 October 2019; Published: 29 October 2019

check for updates

\begin{abstract}
Prostate specific membrane antigen (PSMA) has become a major focus point in the research and development of prostate cancer (PCa) imaging and therapeutic strategies using radiolabeled tracers. PSMA has shown to be an excellent target for PCa theranostics because of its high expression on the membrane of PCa cells and the increase in expression during disease progression. Therefore, numerous PSMA-targeting tracers have been developed and (pre)clinically studied with promising results. However, many of these PSMA-targeting tracers show uptake in healthy organs such as the salivary glands, causing radiotoxicity. Furthermore, not all patients respond to PSMA-targeted radionuclide therapy (TRT). This created the necessity of additional preclinical research studies in which existing tracers are reevaluated and new tracers are developed in order to improve PSMA-TRT by protecting the (PSMA-expressing) healthy organs and improving tumor uptake. In this review we will give an overview of the recent preclinical research projects regarding PCa-TRT using PSMA-specific radiotracers, which will give an indication of where the PSMA-TRT research movement is going and what we can expect in future clinical trials.
\end{abstract}

Keywords: prostate specific membrane antigen; prostate cancer; targeted radionuclide therapy

\section{Introduction}

Prostate cancer (PCa) is a major public health problem; approximately 450,000 men have been diagnosed with PCa in Europe in 2018 [1]. Although the 5 year survival rate for local and regional PCa is $99 \%-100 \%$, this rate drops to $30 \%$ for patients with metastasized PCa [2]. Currently, prostate-specific antigen (PSA) level measurements, digital rectal examination, and Gleason score grading are being used for the diagnosis and staging of PCa. Current treatment options for PCa patients involve surgery and radionuclide therapy for local disease, while hormone therapy, anti-androgen therapy, and chemotherapy are therapeutic options for advanced disease [3]. Patients at high risk for metastatic disease, based on high plasma PSA, but with negative prostate biopsy or patients with rising PSA levels after local treatment with curative intent, undergo additional staging using computed tomography (CT), whole body magnetic resonance imaging (MRI), or ${ }^{18} \mathrm{~F}$ choline-based positron emission tomography (PET)/CT. These imaging techniques unfortunately have limited sensitivity for detecting small metastatic lesions [4].

In 1987, the type II transmembrane enzymatic protein prostate specific membrane antigen (PSMA) was discovered as a novel antigenic marker in PCa cells and serum of PCa patients [5]. PSMA is overexpressed in $90 \%-100 \%$ of PCa cases and the level of PSMA expression is highly correlated 
with disease progression, with high PSMA expression being found in hormone-resistant tumors and metastases [6-8]. The overexpression of PSMA on (metastasized) PCa cells makes it an excellent target for imaging and therapy using PSMA-targeting tracers. These tracers can be labeled with different varieties of radionuclides for diagnostic (e.g., positron emitter gallium-68) or therapeutic purposes (e.g., beta-particle emitter lutetium-177 or alpha-particle emitter actinium-225). The radiolabeled tracers are administered intravenously and will accumulate at the tumor sites due to their PSMA-targeting properties. Radioactive decay of the alpha and beta particle emitting radionuclides can induce DNA damage which ultimately may lead to cancer cell death. The excellent potential application of PSMA-targeting tracers resulted in the development of a multitude of different tracers for diagnostic and therapeutic purposes.

The high interest in PSMA-targeted radionuclide therapy (TRT) led to a quick movement from preclinical research to clinical trials, which are showing very promising results. However, next to PCa cells, expression of PSMA is also found in healthy prostate tissue, the small intestine, central nervous system, proximal renal tubules, and the salivary and lacrimal glands [9-11]. These PSMA-expressing organs show uptake of almost all PSMA-targeting radiotracers, which might cause toxicity. Especially when using an alpha particle-emitting radionuclide (e.g., actinium-225), severe xerostomia can occur, which can have an enormous negative impact on the quality of life of the patients [12].

The high number of developed PSMA-specific tracers and their almost immediate transit to clinical trials offered a major advantage in the treatment of metastasized PCa patients. However, as described above, many tracers showed uptake in healthy organs causing radiotoxicity and not all patients responded to PSMA-TRT [13]. This created the necessity of additional preclinical research studies in which existing tracers were reevaluated and improved tracers were developed.

In this review we will give an overview of the recent preclinical research projects regarding PCa TRT using PSMA-specific radiotracers, with special emphasis on small molecule PSMA inhibitors. Figure 1 summarizes the preclinical approaches discussed in this review. 

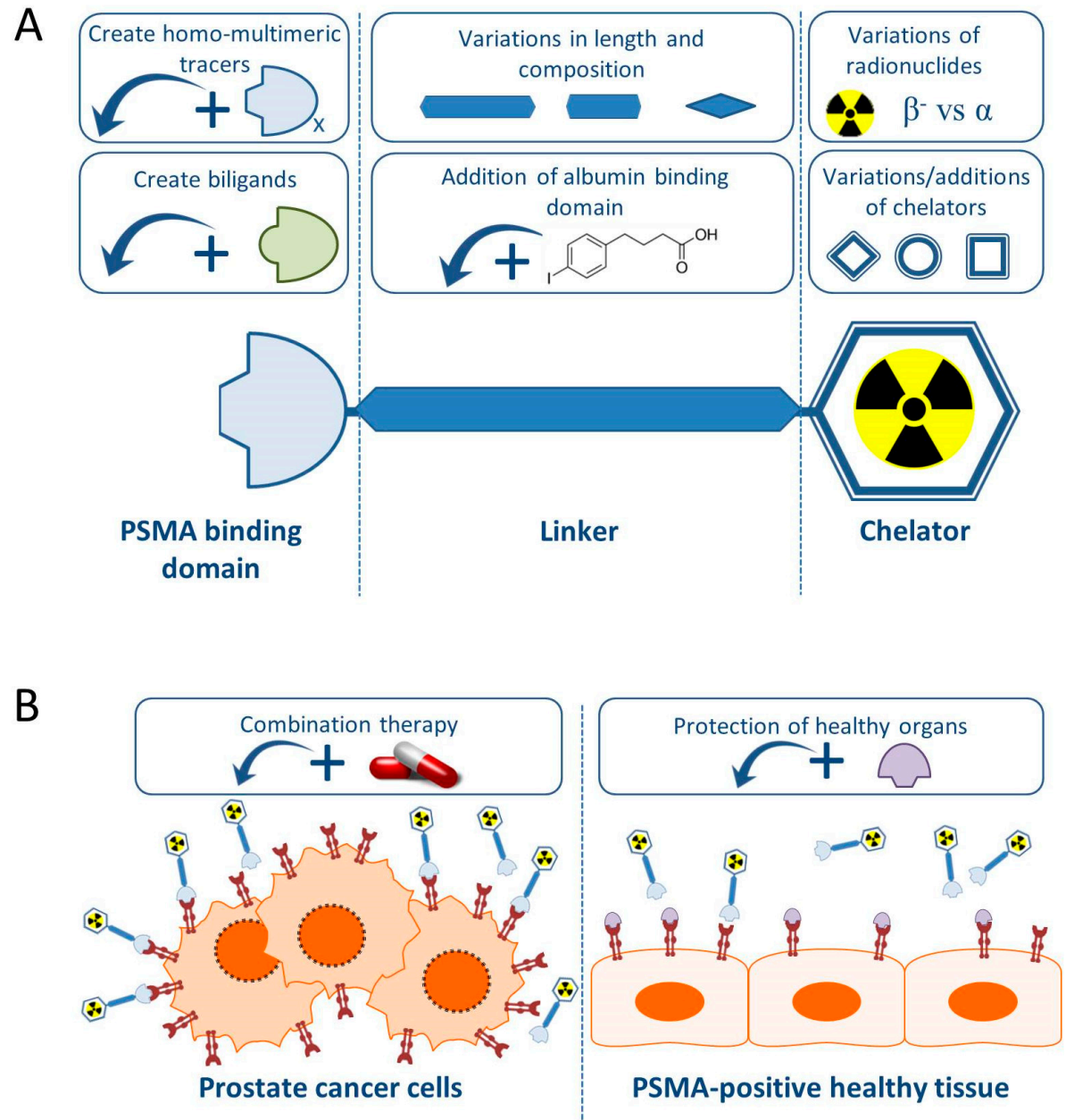

Figure 1. Schematic overview of preclinical research regarding the improvement of prostate specific membrane antigen-targeted radionuclide therapy (PSMA-TRT). (A) The basic building blocks of a PSMA-targeting small molecule inhibitor consist of a PSMA-binding domain, a linker and a chelator which can be labeled with various radionuclides. For each part of the tracer, additions or variations are being preclinically studied and described in this review. (B) Next to alterations to the targeting molecule, increasing the therapeutic impact on the tumor (left) is tried by combining PSMA-TRT with for instance androgen deprivation therapy. Protection of the healthy PSMA-expressing tissue (right) is studied by blocking the PSMA-molecule with for instance 2-PMPA.

\section{PSMA-Targeting Small Molecule Inhibitors}

Generally, PSMA-targeting small molecule inhibitors consist out of a PSMA binding domain, a linker and a domain to which radionuclides can be labeled, such as the chelator 1,4,7,10-tetraazacycloododecane- $N, N^{\prime}, N^{\prime \prime}, N^{\prime \prime \prime}$-tetraacetic acid (DOTA) or 1,4,7,10-tetraazacyclododececane,1-(glutaric acid)-4,7,10-triacetic acid (DOTAGA) (Figure 1).

The development of PSMA-targeting small molecule inhibitors skyrocketed from the moment it was discovered that PSMA is chemically identical to NAALADase ( $N$-acetyl-alphalinked-acidic-dipeptidase), a neurotransmitter catalyzer, and to folate hydrolase 1 (FOLH-1), which is expressed in the jejunal brush border [14]. Already existing inhibitors of NAALDase could therefore be used as PSMA-targeting tracers. Furthermore, numerous other small molecule inhibitors have been derived and some of those are currently being studied in clinical trials (Table 1). An elaborate overview of PSMA-targeting tracer development in the past two decades can be found in earlier published reviews [15-21].

PSMA-targeting small molecule inhibitors can be divided into three types; urea-based, phosphorus-based, and thiol-based. The urea-based compounds have shown superior binding 
affinity for PSMA compared to the other two types. Hence, most (novel) PSMA-specific small molecule inhibitors carry the urea-based binding domain [22]. These urea-based PSMA binding motifs are present in three forms: glutamate-urea-lysine (glu-urea-lys), glutamate-urea-glutamate (glu-urea-glu), or glutamate-urea-cysteine (glu-urea-cys) [23].

Today, PSMA-617 and PSMA-I\&T are the tracers most often applied to PSMA-TRT in preclinical research and clinical trials. Both share the same glu-urea-lys-PSMA binding motif and their DOTA/DOTAGA chelators enable labeling with therapeutic radionuclides [24,25].

Table 1. Overview of PSMA-targeting small molecule inhibitors suitable for therapy.

\begin{tabular}{|c|c|c|c|c|}
\hline Compound & Radionuclides & PSMA Binding Motif & First Reference & Clinical Trials \\
\hline PSMA-617 & $\begin{array}{c}\text { Lutetium-177 } \\
\text { Actinium-225 } \\
\text { Indium-111 } \\
\text { Gallium-68 } \\
\text { Yttrium-90 }\end{array}$ & $\begin{array}{c}\text { Urea based } \\
\text { (Glu-urea-lys) }\end{array}$ & [26] & {$[27,28]$} \\
\hline PSMA-I\&T & $\begin{array}{c}\text { Lutetium-177 } \\
\text { Actinium-225 } \\
\text { Indium-111 } \\
\text { Gallium-68 }\end{array}$ & $\begin{array}{c}\text { Urea based } \\
\text { (Glu-urea-lys) }\end{array}$ & [29] & [30] \\
\hline MIP-1095 & $\begin{array}{l}\text { Iodine-123 } \\
\text { Iodine-131 }\end{array}$ & $\begin{array}{c}\text { Urea based } \\
\text { (Glu-urea-lys) }\end{array}$ & [31] & [32] \\
\hline MIP-1072 & Iodine-123 & $\begin{array}{c}\text { Urea based } \\
\text { (Glu-urea-lys) }\end{array}$ & [31] & [33] \\
\hline MIP-1404/-1405 & Technetium-99m & $\begin{array}{c}\text { Urea based } \\
\text { (Glu-urea-lys) }\end{array}$ & [34] & [35] \\
\hline PSMA I\&S & Technetium-99m & $\begin{array}{c}\text { Urea based } \\
\text { (Glu-urea-lys) }\end{array}$ & [36] & - \\
\hline CTT1400/CTT1402 & Lutetium-177 & phosphoramidate-based & [37] & - \\
\hline RPS-027 & $\begin{array}{c}\text { Iodine-131 } \\
\text { Astatine-211 }\end{array}$ & $\begin{array}{c}\text { Urea based } \\
\text { (Glu-urea-lys) }\end{array}$ & [38] & - \\
\hline DCIBzL & $\begin{array}{l}\text { Iodine-125 } \\
\text { Iodine-131 }\end{array}$ & $\begin{array}{c}\text { Urea based } \\
\text { (Glu-urea-lys) }\end{array}$ & [39] & - \\
\hline
\end{tabular}

\section{Improving PSMA-Targeting Small Molecule Inhibitors}

Despite the promising results of numerous clinical trials with PSMA-targeting small molecule inhibitors labeled with beta particle-emitting or alpha particle-emitting radionuclides, a necessity for optimization of these tracers has become prominent because of the healthy organ toxicity discussed above $[40,41]$. Therefore, the majority of preclinical research is focused on developing and/or adjusting PSMA-targeting tracers to make them safer and better. Different strategies to optimize the tissue distribution characteristics of the current PSMA-targeting tracers are being applied, for instance by adding an albumin binding domain or by linker modifications, intending to prevent the uptake in the salivary glands and kidneys and increase tumor binding.

\subsection{Addition of an Albumin Binding Domain}

A possible method to reduce toxicity on healthy organs during PSMA-TRT would be to decrease the injected dose of radiolabeled tracer. However, this might probably lead to a reduction of anti-tumor efficacy. This problem could be overcome by elongation of the circulation time of the radiolabeled tracers, most likely leading to an increase in tumor uptake. In this way, a lower quantity of the radiolabeled tracer can be injected while reaching the same level of tumor targeting [42]. 
The circulation time of rapidly cleared molecules can effectively be increased by adding a plasma protein binding domain [43]. Albumin is an ideal plasma protein target as it is the most abundant protein in the blood and has a half-life of 19 days in the human blood circulation [44,45]. Next to the advantage of the increased circulation time, addition of an albumin binding domain is suggested to have extra advantages. For instance, due to the increased size of the conjugated tracer, the chance that the radiolabeled compound can accumulate in the tumor increases due to the leaky tumor vasculature versus the impermeable vascular walls of the healthy tissue [46]. Furthermore, it is suggested that tumor uptake of albumin conjugated tracers will increase because of the overexpression in the tumor environment of albumin-binding proteins such as secreted protein acidic and rich in cysteine SPARC and the glycoprotein 60 (gp60) receptor, which play crucial roles in angiogenesis and capillary permeability, respectively [47].

The principle of adding an albumin binding domain to increase the circulation time and decrease normal tissue binding of radiolabeled compounds was first proven by Müller et al., who measured the binding of [ $\left.{ }^{177} \mathrm{Lu}\right] \mathrm{Lu}-\mathrm{cm} 09$, a folate ligand with an albumin binding domain [48]. This research showed a $3 \times$ higher in vivo tumor uptake $24 \mathrm{~h}$ post injection (p.i.) and a $2.5 \times$ lower kidney uptake $4 \mathrm{~h}$ p.i. of the folate ligand with albumin binding domain compared to $\left[{ }^{177} \mathrm{Lu}\right] \mathrm{Lu}$-EC0800, the same folate ligand without albumin binding domain. Subsequently, several research groups conjugated the 4-(p-iodophenyl)butyric acid as an albumin binding domain to PSMA-targeting small molecule inhibitors tracers [37,38,49-51]. These PSMA-albumin binding tracers (CTT1403, RPS-027, RPS-063, DOTA-PSMA-ALB-02 and HTK01169) all successfully showed increased circulation-half-lives and tumor uptake. However, unlike the findings of Müller et al. with the folate ligands [48], the addition of this albumin binding domain also dramatically increased the renal uptake for these tracers during in vivo murine experiments, which may be caused by the increased circulation time. Similar results were presented by Wang et al. who coupled the truncated Evans blue (tEB) albumin binding domain to their PSMA-targeting compound (DOTA-EB-MCG) [46].

Follow-up studies aimed to exploit the increased tumor uptake and tried simultaneously to prevent the increased renal uptake. For this, Umbricht et al. compared the 4-( $p$-iodophenyl)butyric acid with a $p$-(tolyl)-moiety as an albumin binding domain conjugated to the DOTA-PSMA-617 compound, creating PSMA-ALB-53 and PSMA-ALB-56, respectively [52]. The $p$-(tolyl)-moiety is a weaker albumin binder compared to PSMA-ALB-53 and showed a faster in vivo renal clearance when labeled with lutetium-177. Interestingly, $\left.{ }^{[77} \mathrm{Lu}\right] \mathrm{Lu}-\mathrm{PSMA}-\mathrm{ALB}-56$ demonstrated a higher tumor uptake compared to $\left[{ }^{177} \mathrm{Lu}\right] \mathrm{Lu}-\mathrm{PSMA}-\mathrm{ALB}-53$ which led to a $3 \times$ higher tumor-to-kidney ratio of $\left[{ }^{177} \mathrm{Lu}\right] \mathrm{Lu}-\mathrm{PSMA}-\mathrm{ALB}-56$ compared to [ $\left.{ }^{177} \mathrm{Lu}\right] \mathrm{Lu}-\mathrm{PSMA}-\mathrm{ALB}-53$. In vivo therapy studies showed an increased survival benefit of $\left[{ }^{177} \mathrm{Lu}\right] \mathrm{Lu}-\mathrm{PSMA}-\mathrm{ALB}-56$ compared to $\left[{ }^{177} \mathrm{Lu}\right] \mathrm{Lu}-\mathrm{PSMA}-617$, probably due to its higher tumor uptake. However the tumor-to-kidney ratio of [ $\left.{ }^{177} \mathrm{Lu}\right] \mathrm{Lu}$-PSMA-617 was $3 \times$ higher compared to $\left[{ }^{177} \mathrm{Lu}\right] \mathrm{Lu}-\mathrm{PSMA}-\mathrm{ALB}-56$. The use of a weaker albumin binder might be an ideal compromise leading to increased tumor uptake due to the albumin binding, although with enhanced risk for renal toxicity.

Summarized, increased circulation half-life of a PSMA-targeting radiotracer by addition of an albumin binding domain successfully increased tumor uptake. However, the concomitant significant increase in renal uptake is unfavorable and should be prevented. Moreover, the longer circulation time of these adapted tracers might also lead to increased bone marrow toxicity as well as toxicity in the salivary and lacrimal glands of PCa patients, which has a major negative impact on the quality of life of these patients. Table 2 gives an overview of the developed albumin binding compounds described here. 
Table 2. Overview of PSMA-targeting small molecule inhibitors that have been conjugated with an albumin binding domain and their in vivo biodistribution data in mice. ${ }^{*}$ Values had to be based on graphs rather than exact data as they were not present in the reference.

\begin{tabular}{|c|c|c|c|c|c|c|}
\hline Compound & Radionuclide & Albumin Binding Domain & In Vivo Model & Injected & Tumor-to-kidney-Ratio 24 h p.i. & Ref. \\
\hline CTT1402 & Lutetium-177 & 4-(p-iodophenyl) butyric acid & NCr nude mice + PC3-PIP tumors & $\begin{array}{l}1.85 \pm 0.07 \mathrm{MBq} \\
4 \pm 1 \mathrm{MBq} / \mathrm{nmol}\end{array}$ & 0.14 & [37] \\
\hline RPS- 027 & Iodine-131 & 4-(4-iodophenyl) butanoic acid & NCr-nu/nu mice + LNCaP cell xenografts & $\sim 370 \mathrm{kBq} / 10 \mu \mathrm{Ci}$ & $\pm 2.5^{*}$ & [38] \\
\hline DOTA-PSMA-ALB-02 & Lutetium-177 & 4-(p-iodophenyl) butyric acid & PC-3 PIP/flu & No data & 7.16 & [50] \\
\hline HTK01169 & Lutetium-177 & $N$-[4-(p-iodophenyl)butanoyl]-Glu & LNCaP & No data & 0.45 & [51] \\
\hline DOTA-EB-MCG & Yttrium-90 & truncated Evans blue & Athymic Nude-Foxn1nu, Envigo + PC3-PIP tumors & $3.7-5.1 \mathrm{MBq}$ & $\pm 4^{*}$ & [46] \\
\hline RPS-072 & Lutetium-177 & 4-(4-iodophenyl) butanoic acid & Male BALB/C athymic nu/nu mice + LNCaP tumors & $\begin{array}{c}0.36-1.3 \mathrm{MBq} \\
13-23 \mathrm{pmol}\end{array}$ & $\pm 4.5^{*}$ & [53] \\
\hline RPS-074 & Actinium-225 & 4-(4-iodophenyl) butanoic acid & Male BALB/C athymic nu/nu mice + LNCaP tumors & $105 \mathrm{kBq} 142 \mathrm{pmol}$ & 4.3 & [54] \\
\hline PSMA-ALB-53 & Lutetium-177 & 4-(p-iodophenyl)-moiety & PC3-PIP tumors & $5 \mathrm{MBq} 100 \mathrm{pmol}$ & 2.17 & [52] \\
\hline PSMA-ALB-56 & Lutetium-177 & $p$-(tolyl)-moiety & PC3-PIP tumors & 5MBq $100 \mathrm{pmol}$ & 10.8 & [52] \\
\hline
\end{tabular}




\subsection{Linker and Chelator Modifications}

Other structural modifications of small molecule inhibitors have been reported in attempts to improve the therapeutic efficacy and tumor-to-background ratios. One option is to change the linker molecule in between the PSMA binding domain and chelator, since there is increasing evidence that PSMA-binding is not only caused by the PSMA-binding motif in these molecules, but also the hydrophobicity, charge, and overall structure is thought to influence PSMA binding efficacy [55]. Furthermore, it is suggested that binding of PSMA-targeting tracers to, for instance, the salivary glands might also be due to the hydrophobic character of the linker [56]. Therefore, modification of the linker can have significant impact on binding affinity, biodistribution, and overall pharmacokinetic properties of PSMA-targeting small molecule inhibitors [57].

Benesova et al. first showed that modifying the linker between the PSMA-binding domain and the DOTA chelator can significantly influence the pharmacokinetic properties by optimizing the linker moiety when creating PSMA-617 small molecule inhibitors [26]. Eighteen chemically different PSMA-targeting small molecule inhibitors were developed by altering the configuration of the linker. This resulted in significant changes in the pharmacokinetic properties of the tracers, thereby providing evidence that linker modification can have an impact on pharmacokinetic properties. The changes in these linkers did however not lead to superior tumor-targeting and pharmacokinetic properties compared to PSMA-617. By experimenting with these different linkers, the researchers generated knowledge of the binding effects of structural changes in PSMA-targeting tracers and proposed that this may lead to a more rational and structure-aided design and synthesis of novel PSMA-targeting small molecule inhibitors [55].

Schmidt et al. conjugated a carbohydrate to the linker of PSMA-I\&T as a strategy to reduce the unwanted renal accumulation. They successfully showed the feasibility of the conjugation of such a bulky carbohydrate moiety to PSMA-I\&T. This conjugation had no negative effect on the target affinity; however, the in vitro internalization rate decreased considerably. Furthermore, no beneficial effects were shown of the conjugated carbohydrate moiety in vivo [58]. Another linker modification to a PSMA small molecule inhibitor suitable for therapy was tested by Kuo et al. The authors replaced the 2-naphthylalanine (2-Nal) amino acid of the linker of PMSA-617 with either 2-indanylglycine (Igl) or 3,3-diphenylalanine (Dip), which are close analogs of 2-Nal. Doing so, the researchers hypothesized that these changes would lead to a stronger interaction with the PSMA target. However, the substitution with Igl or Dip led to a 5- and 21-fold decrease, respectively, of in vitro binding affinity. The compound with the Igl substitution (HTK01166) showed similar in vivo tumor binding as PSMA-617, however an almost $5 \times$ higher renal uptake. The Dip replacement (HTK01167) on the other hand, led to a $6 \times$ lower kidney binding and a $2 \times$ lower tumor binding. This indicates the potential of HTK01167 as a theranostic tracer with lower tumor-background ratios and warrants further development [59].

Kelly et al. tried to optimize the binding characteristics of their developed albumin binding PSMA-tracer RPS-63 via an increased polyethylene glycol (PEG) spacer length between the PSMA binding domain and the albumin binding domain. The newly synthesized RPS-072 showed a higher tumor uptake compared to RPS-63 and PSMA-617. The researchers argued that the increased linker size reduced the retention of the radioligand by increasing its clearance before the tubular reabsorption. However, besides increased tumor uptake, renal uptake of RPS-072 increased as compared to PSMA-617 [49].

These examples of linker modifications support the hypothesis that linker structure has an influence on tracer pharmacokinetic properties and show the feasibility of alternating the structure. However, none of the previous discussed modifications has led to an increased tumor binding and a decrease in the binding to the healthy PSMA-expressing organs in comparison to PSMA-617 or PSMA-I\&T, respectively.

In addition to altering linker structure, the chelating moiety is also interchangeable and can have a significant effect on the pharmacokinetics [60,61]. For example, replacing the DOTA chelator of PSMA-617 with a CHX-A"-DTPA conjugate, Wüstemann et al. showed higher in vitro internalization rate facilitated by the CHX-A"-DTPA chelator compared to PSMA-617. Furthermore, a progressive 
long-term accumulation in LNCaP tumors in vivo was observed, as the CHX-A"-DTPA conjugate uptake increased until $3 \mathrm{~h}$ p.i. The researchers suggested that this was due to the higher internalization rate that they measured in vitro. However, it must be noted that the DOTA version of PSMA-617 has an approximately $2 \times$ higher tumor uptake in vivo [57].

Next to changing the chelator moiety of PSMA-targeting tracers, also the addition of an extra chelator is being investigated as a method to label compounds with both therapeutic and diagnostic radionuclides. For instance, Wurzer et al. synthesized such a dual-nuclide labeled tracer (gallium-68 for PET and bismuth-213 for therapy) and proved the concept of in vivo monitoring the biodistribution via PET and therefore enabling precise therapeutic dosimetry. Limitation of this approach is that radionuclides with matching half-lifes must be used in order to correctly determine dosimetry [62]. In line of this research, Wester et al. proposed the idea for a PSMA radiohybrid (rhPSMA) tracer that consists of a PSMA binding domain, a radiometal binding chelator and an extra functional group for covalent fluorine-18 labeling. This rhPSMA tracer will be suitable for PET imaging when labeled with fluorine-18 and the chelator is filled with a cold/non-radioactive metal, like lutetium-175. When using this tracer for therapy, the rhPSMA tracer can be labeled with lutetium-177 and fluorine-19. Using this approach, the tracer used for diagnostic PET imaging and the tracer used for therapy are chemically 100\% identical. These rhPSMA tracers therefore will have the same binding affinities, selectivities, lipophilicities, and pharmacokinetics. This has the advantage of pretherapeutic PET-imaging providing valid quantitative biodistribution data and dosimetry, which can be used for personal therapeutic intervention [25].

Thus, the structure of the linker and the type of chelator can have an effect on the overall binding properties of PSMA-specific agents. Experiments with structural differences in these tracers gives more insight in PSMA-binding and internalization both in PCa and healthy PMSA-expressing organs and further research is warranted.

\section{Development of Multi- and Bi-Ligands}

In order to increase the binding affinity of PSMA-specific tracers, some groups have focused on the development of homo-multimeric tracers, which contain more than one PSMA-binding domain [62-64]. These multivalent PSMA-specific tracers have shown promising results in vitro, increased binding affinity, and in vivo, increased tumor retention. However, these tracers have not been introduced in the clinic for therapeutic purposes yet.

Looking beyond PSMA, PCa cells also express other target proteins that are suitable for TRT. Combining a PSMA-targeting tracer with a tracer targeting another PCa specific target might increase uptake in PCa lesions and show enhanced theranostic properties. The probability of a double targeting tracer, or biligand, to bind to PCa is larger especially of value for tumors with a high heterogeneity in expression of different targets $[65,66]$. However, combination of two targeting molecules might also have the drawback of interfering with binding to the PSMA target or increasing binding on PSMA-expressing or other healthy organs. Furthermore, increasing the size of PSMA-targeting tracers may have negative effects on the pharmacokinetic properties.

\subsection{Targeting PSMA and Hepsin/Integrins}

Various bi-ligands have been developed in which PSMA-targeting tracers are combined with another specific binding domain. For example, Subedi et al. combined a Lys-urea-Glu moiety PSMA-binding scaffold with a binding domain targeting hepsin, a membrane serine protease that is highly upregulated in PCa [67]. Conjugated with the optical dye SulfoCy7, this compound showed higher binding in PSMA- and hepsin-expressing tumors compared to tracers that target PSMA alone, which suggests that this PSMA/hepsin heterodimer might be useful in increasing sensitivity of PCa diagnostic imaging [68]. A PSMA-hepsin heterodimer suitable for radionuclide therapy and the corresponding healthy organ uptake has not been investigated yet. 
Another example that proves the feasibility of creating PSMA heterodimers is provided by Shallal et al. Here, the authors combined the PSMA binding domain with a domain targeting $\alpha_{\mathrm{v}} \beta_{3}$ integrin reported to be highly upregulated in PCa. The researchers were able to prove in vitro that the PSMA $/ \alpha_{\mathrm{v}} \beta_{3}$ integrin heterodimer could bind to both targets; however, the binding affinity was much lower compared to DCIBzL, a high affinity PSMA binding agent. This compound is being taken further into preclinical testing by performing quantitative biodistribution assays and imaging in vivo [69].

\subsection{Targeting PSMA and the Gastrin-Releasing Peptide Receptor}

Another relevant PCa target is the gastrin-releasing peptide receptor (GRPR). GRPR is a transmembrane G-protein coupled receptor which is overexpressed in $84 \%$ of PCa cases, as well as in other types of cancer, such as breast cancer and small cell lung cancer [70,71]. Beside expression in tumor tissue, GRPR is expressed in various healthy tissues, such as breast, pancreas, prostate, and lung [72]. While PSMA expression increases as the disease progresses, GRPR is already overexpressed in high levels in early PCa stages [71]. Therefore, combined targeting of both PSMA and GRPR could lead to a high tumor uptake during all disease stages.

In 2014, the first PSMA/GRPR heterodimer ((DUPA-6-Ahx-( $\left.\left.{ }^{64} \mathrm{Cu}-\mathrm{NODAGA}\right)-5-\mathrm{Ava}-\mathrm{BBN}(7-14) \mathrm{NH}_{2}\right)$ ) was created by Bandari et al. with the aim to improve PCa imaging [73]. Although this compound did not show superior imaging properties compared to existing mono-targeting PSMA-tracers, the study did show that constructing such a PSMA/GRPR targeting tracer was feasible. Rapidly, several PSMA/GRPR targeting heterodimers were developed and preclinically tested [66,70]. These PSMA/GRPR bi-ligands all showed specific PSMA and GRPR PCa tumor targeting in vitro and in vivo. However, the combination of the two targeting domains also combined with undesired high uptake in the kidneys, spleen, and pancreas. Alterations in the linker compositions by increasing the number of charged amino acids resulted in a significant decreased uptake in the kidneys and spleen. Unfortunately, it also resulted in increased uptake of the GRPR-positive pancreas [65].

Because research models of PCa used in the previously described research projects only overexpress either PSMA or GRPR, but not both targets simultaneously, it is yet impossible to show that combining these targets will have a synergistic or additive tumor targeting effect. Abouzayed et al. did use an in vivo tumor model that both expresses PSMA and GRPR, PC3-PIP, while studying their GRPR/PSMA-heterodimer [25I]I-BO530 [74]. [ $\left.{ }^{125} \mathrm{I}\right] \mathrm{I}-\mathrm{BO} 530$ showed long activity retention in these PC3-PIP tumors however, high uptake in the kidneys led to unfavorable low tumor-to-kidney ratios of $1.2 \pm 0.3$ at $24 \mathrm{~h}$ p.i. which, so the researchers argue, could lead to an unacceptably high renal radiation dose. Furthermore, the researchers did not compare $\left[{ }^{125} \mathrm{I}\right] \mathrm{I}-\mathrm{BO} 530$ to a single PSMA-targeting tracer (for instance PSMA-617), which is necessary in order to prove synergistic advantages of the PSMA-GRPR heterodimer.

These studies showed that it is feasible to create heterodimer tracers that target both PSMA and GRPR. However, it must be noted that with the addition of the GRPR moiety, the salivary glands and kidney toxicity caused by PSMA-TRT might be accompanied by the GRPR-TRT toxicity in GRPR-expressing pancreas. This must be carefully considered before introducing these bi-ligands to the clinic.

\section{Varying Radionuclides for PSMA-TRT}

There are different types of radionuclide emissions that can cause cellular/DNA damage and therefore can be used for therapeutic purposes; Auger/conversion electrons and beta- $\left(\beta^{-}\right)$and alpha $(\alpha)$ emission (Figure 2). These emissions have different linear energy transfer (LET, in Kev/um) values ranging from a few $\mathrm{eV}$ for Auger/conversion electrons up to $\mathrm{MeV}$ for alpha particles (Table 3). Importantly, the range of these particles varies. While alpha and beta radiation reaches a range of $40-100 \mu \mathrm{m}$ and 50-12,000 $\mu \mathrm{m}$, respectively, Auger/conversion electrons have a very short range of only 0.002-0.5 $\mu \mathrm{m}$ [75]. Delivery of the radiolabeled compounds which carry a radionuclide with such a short range must therefore be very close to or directly in/near the cell nucleus in order to cause DNA damage. 

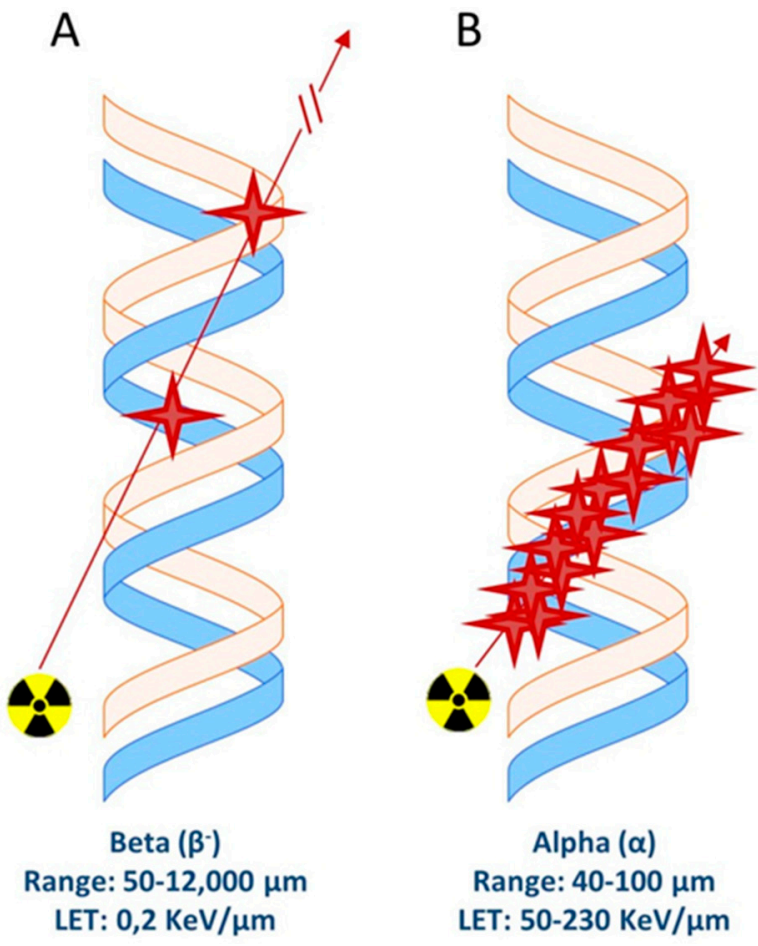

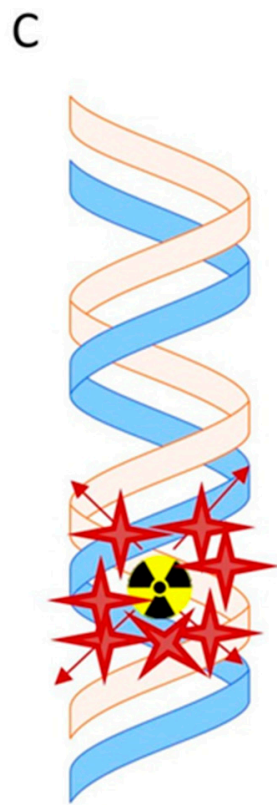

Auger electrons
Range: $0.002-0.5 \mu \mathrm{m}$
LET: $4-26 \mathrm{KeV} / \mu \mathrm{m}$

Figure 2. Schematic representation of ionization events caused by (A) beta particles, (B) alpha particles, and $(\mathbf{C})$ Auger electrons.

Table 3. Overview of radionuclides used in PSMA-TRT (pre)clinical research and their basic characteristics.

\begin{tabular}{cccc}
\hline Radionuclide & Particle Emission & $\mathbf{T}_{\mathbf{1 / 2}}$ & $\operatorname{Eavg~KeV~}\left(\beta^{-}\right.$or $\left.\alpha\right)$ \\
\hline Scandium-47 & $\beta^{-}$ & 3.3 days & 162 \\
Copper-67 & $\beta^{-}$ & 2.6 days & 141 \\
Iodine-131 & $\beta^{-}$ & 8.0 days & 181 \\
Terbium-161 & $\beta^{-}$ & 6.9 days & 154 \\
Lutetium-177 & $\beta^{-}$ & 6.7 days & 140 \\
Astatine-211 & $\alpha$ & $7.2 \mathrm{~h}$ & 5868 \\
Lead-212 & $\beta^{-}$ & $10.6 \mathrm{~h}$ & 130 \\
Bismuth-213 & $\alpha$ & 46 min & $1390(\max )$ \\
Actinium-225 & $\alpha$ & 9.9 days & 5915 \\
Thorium-227 & $\alpha$ & 18.7 days & 6145 \\
\hline
\end{tabular}

\subsection{Beta-Emitters}

Today, lutetium-177 is most frequently used for PSMA-TRT in the (pre)clinic. With a mean range of $670 \mu \mathrm{m}$ and energies of $0.1-2.2 \mathrm{MeV}$ of the beta particles, it is an ideal radionuclide for treatment of micro-metastases. Lutetium-177 also emits $\gamma$-rays during its decay, enabling single photon emission computed tomography (SPECT) imaging for treatment efficacy predictions. Despite these favorable properties, clinical studies have shown that approximately $30 \%$ of PCa patients did not respond to lutetium-177 PSMA-TRT [76,77]. Therefore, many (pre)clinical research projects focus on experimenting with different radionuclides to reach a higher therapeutic efficiency.

Alternative potent beta-emitting radionuclides are copper-67, scandium-47 and terbium- 161 . These radionuclides have an energy emission comparable to that of lutetium-177 [78]. Müller et al. studied the potency of terbium-161 for PSMA-TRT, which, besides beta decay, also emits a considerable amount of Auger/conversion electrons, leading to a possible increase in total absorbed dose compared to lutetium-177 [79]. In vivo biodistribution assays revealed comparable biodistribution profiles for PSMA-617 labeled with lutetium-177 or terbium-161. In vitro, [ $\left.{ }^{161} \mathrm{~Tb}\right] \mathrm{Tb}-\mathrm{PSMA}-617$ had a significantly higher therapeutic efficiency on PC3-PIP cells compared to [ $\left.{ }^{177} \mathrm{Lu}\right] \mathrm{Lu}-\mathrm{PSMA}-617$. An in vivo therapy 
study comparing [ $\left.{ }^{177} \mathrm{Lu}\right] \mathrm{Lu}-\mathrm{PSMA}-617$ and $\left[{ }^{161} \mathrm{~Tb}\right] \mathrm{Tb}-\mathrm{PSMA}-617$ is currently lacking, indicating that additional pre-clinical research is needed to test the potential of these tracers.

\subsection{Alpha-Emmiters}

Targeted alpha therapy (TAT) has become of high interest for PSMA-TRT. Alpha particles have much higher LET and a shorter range compared to beta-particles, which can lead to several ionization events in close proximity to each other within the DNA causing so-called alpha-tracks $[80,81]$. Therefore, in comparison to beta decay, alpha decay can cause a high quantity of DNA double strand breaks in a short range and holds the promise of a higher level of induced DNA damage per cell. Actinium-225, lead-212, thorium-227, bismuth-213, and astatine-211 are alpha emitting radionuclides that are being explored (pre)clinically for PSMA-TAT $[54,80,82,83]$. These studies all prove the increased therapeutic effectiveness of alpha-radiation compared to beta-radiation. Mice treated with a single dose of $\left[{ }^{225} \mathrm{Ac}\right]$ Ac-RPS-074 $(148 \mathrm{kBq})$ even showed total remission underlining the potential of actinium-225 for PSMA-directed radionuclide therapy [54]. The increase in therapeutic efficiency by the use of alpha-radiation, however, may also lead to an increase in (late) onset of toxicity. Preclinical in vivo studies did not address these long-term toxicity effects, however, several clinical PSMA-TRT studies with actinium-225 reported irreversible damage to lacrimal and salivary glands, causing xerostomia [84]. Xerostomia is one of the major concerns for PSMA targeting therapy as it has a major negative impact on the quality of life of the patients and should therefore be prevented.

Lead-212 emits beta-particles and decays into bismuth-212, which emits alpha-particles. Lead-212 is suggested as a potent alternative for actinium-225 because of its shorter half-life ( $10 \mathrm{~h}$ vs. 10 days) and fewer alpha emitting daughters ( 1 vs. 3 ), thus potentially lower normal organ toxicity risks $[85,86]$. Banerjee et al. recently published their proof-of-concept of a novel $\left[{ }^{212} \mathrm{~Pb}\right] \mathrm{Pb}-$ labeled L2, a PSMA low molecular weight compound [86]. In vivo murine dose-dependent tumor growth inhibition was demonstrated, resulting in increased survival benefit when compared to [ $\left.{ }^{177} \mathrm{Lu}\right] \mathrm{Lu}-\mathrm{PSMA}-617$. Unfortunately, long term renal toxicity was observed in healthy non-tumor bearing mice after a single administration of $\left[{ }^{212} \mathrm{~Pb}\right] \mathrm{Pb}-\mathrm{L} 2$, revealing the kidneys as dose-limiting organs in mice.

Taken together, various radionuclides with different characteristics have been tested in preclinical experiments for their efficacy and toxicity for PSMA-TRT. Currently, lutetium-177 is most frequently used in the (pre)clinic, followed by actinium-225. Further preclinical and clinical research is required to define the most optimal tracer-radionuclide combination which combines the highest therapeutic efficiency with the lowest toxicity. Further description of current PSMA-TAT research can be found in the review of Chakravarty et al. [40].

\section{Enhancement of Therapy Effect}

So far, we have elaborately discussed the approaches used to develop novel or adjust existing tracers in order to increase the therapeutic efficacy of PSMA-TRT. The variations in tracer structures and combinations are in theory endless and thus might result in the development of a magnitude of different PSMA-targeting tracers. Another strategy in order to reach a higher therapeutic efficacy may be combining PSMA-TRT with other (existing) therapies for PCa $[87,88]$. For example, using other agents to increase the PSMA expression on tumor cells or to increase the radiosensitivity of the tumor could significantly increase PSMA-TRT outcome.

Chemical radiosensitizers are compounds that are intended to increase the level of damage induced by ionizing radiation [89]. This combination strategy has been widely researched and clinically adapted for PCa external beam radiation therapy (EBRT) and has shown promising increases in therapeutic efficacy [90]. Radiosensitizing agents can be divided into three working mechanism categories; agents that dysregulate the cell cycle, agents that inhibit DNA damage repair, and agents that cause oxygenated stress.

Radiosensitization in combination with PSMA-TRT has not yet thoroughly been investigated. Tesson et al. combined and compared the therapeutic effect of PSMA-TRT with several radiosensitizing 
compounds in a preclinical setting [91]. When combining [ $\left.{ }^{131} \mathrm{I}\right] \mathrm{I}-\mathrm{MIP}-1095$ with either an oxidizing agent (disulfiram), p53 pathway inhibitor (nutlin-3), proteasome inhibitor (bortezomib), or a PARP-1 inhibitor (olaparib), the researchers found an increased growth inhibition on LNCaP spheroids in vitro.

Other possible radiosensitizers to combine with PSMA-TRT are androgen deprivation therapy (ADT) or anti-androgens, such as enzalutamide and apalutamide. These treatments are already being used for the treatment of locally advanced PCa and non-metastatic castration-resistant PCa [92-94]. Various clinical studies have reported an overall survival benefit of ADT when combined with EBRT [95-97]. Recent preclinical work has revealed that enzalutamide and apalutamide act as radiosensitizers of EBRT via downregulation of the DNA double strand break repair capacity of PCa cells [98-100]. PSMA expression is thought to be regulated by androgens although reports showed conflicting results. While several studies have reported an increase in the level of PSMA expression in PCa cell-lines and in tumor tissue of patients after ADT [101-103], others describe a downregulation of PSMA expression caused by ADT [104,105]. Preclinical in vivo studies have so far been unsuccessful in showing an additive therapeutic effect on the tumor growth of this combination therapy [106]. Clearly, the added value of ADT in combination with PSMA-TRT and its mechanism of action is unresolved [107].

Alternative combination options, for instance EBRT, immunotherapy or other radiosensitizers that are proposed for increasing PSMA-TRT efficacy need to be further explored. Clearly, more preclinical research is warranted to establish potential synergistic or additive effects of combination therapy with PSMA-TRT.

\section{Protection of PSMA Expressing Kidneys and Salivary Glands}

One of the major disadvantages of PSMA-TRT is the high accumulation of the radiolabeled tracers in healthy PSMA-expressing organs, the kidneys and salivary glands. Despite the high uptake in the kidneys, there is very little reported on renal toxicity after PSMA-TRT. This could be explained by the fact that most patients receive PSMA-TRT as a last-option therapy and therefore follow-up is not long enough to detect (late) onset of renal toxicity [108]. However, when PSMA-TRT will be used for patients that are in an early stage of (high risk) PCa with (oligo)-metastatic disease, renal toxicity might become of major concern [109].

PSMA-TAT with actinium-225 has been reported to cause severe and irreversible salivary gland toxicity leading to xerostomia [110]. Xerostomia can have a major impact on the quality of life of the PCa patients that receive the potentially life-elongating PSMA-TRT: in a recent study, $10 \%$ of the patients chose to discontinue their treatment for this reason [84]. Clinical studies have investigated various strategies in order to find a method to protect the salivary glands. Amongst others, external cooling of the salivary glands with ice-packs, saline irrigation, steroid injection, botulinum toxin injections, and oral administration of folic polyglutamate tablets have been evaluated, but with no significant decrease in salivary gland uptake of PSMA-targeting tracers or in too few patients to enable statistical analysis [25,108,111,112].

There clearly is an urgent need to conduct preclinical research to test strategies to protect the salivary glands from damage during PSMA-TRT. However, the lack of a proper in vivo research model for salivary gland PSMA-TRT damage is a major drawback and relatively few preclinical studies have been published on this topic. Mice have high levels of PSMA expression in the brain, kidneys, and salivary glands, at similar levels to that observed in humans. However, in contrast to humans, mice have very low to no PSMA expression in the prostate and jejunum. Furthermore, despite the high PSMA expression in murine salivary glands, biodistribution assays with various PSMA-targeting tracers did not show any, or very low salivary gland uptake, while renal uptake is similar or even higher in mice compared to humans [113-116]. This difference in PSMA expression might be explained by the difference in PSMA amino acid sequence between humans and mice (91\% similarity). Furthermore, the PSMA structures in murine kidneys and salivary glands have been reported to differ $[117,118]$. 
Finally, the high PSMA binding in the salivary gland in humans may not only be due to PSMA expression, but might also be the result of non-specific binding [119,120].

Roy et al. aimed to identify an animal model that resembles human salivary gland uptake of PSMA-TRT and compared the salivary glands uptake of $\left[{ }^{18} \mathrm{~F}\right] \mathrm{F}-\mathrm{DcFPYL}$ in NCR-nu/nu athymic female mice and F344/SAS Fischer female rats [121]. Biodistribution assays revealed a 2- to 3-fold higher uptake of $\left[{ }^{18} \mathrm{~F}\right] \mathrm{F}-\mathrm{DcFPYL}$ in mice submandibular and sublingual glands compared to that of rats. Additional in vitro autoradiography studies on human, mouse, and rat salivary glands showed similar binding of $\left[{ }^{18} \mathrm{~F}\right] \mathrm{F}-\mathrm{DcFPYL}$ for the mouse and human salivary glands. Therefore, they argued that this mouse model is a more suitable research model for PSMA-TRT compared to the rat. However, since the relative uptake of the PSMA-targeted tracer in the murine salivary glands in this study was not comparable to the high uptake in the human salivary glands, it is still questionable whether the NCR-nu/nu mice represent an appropriate research model to examine PSMA-TRT toxicity effects.

Despite the lack of preclinical models that adequately resemble human salivary gland uptake of PSMA-targeting tracers, a few studies reported on protective strategies for the salivary glands and/or kidneys. Rousseau et al. used LNCap-tumor bearing NOD SCID gamma (NSG) mice to demonstrate that administration of monosodium glutamate (MSG), a well-known food additive, can reduce uptake of $\left[{ }^{68} \mathrm{Ga}\right] \mathrm{Ga}-\mathrm{PSMA}-11$ in the salivary glands and kidneys without affecting uptake in the tumor. Because the majority of PSMA ligands integrate glutamate to bind to PSMA, the administration of MSG may act by blocking this process and thereby decreasing non-specific binding in healthy organs [122].

Another strategy that was tested, was the use of 2-(phosphonomethyl)pentane-1,5-dioic acid (2-PMPA), a well-known PSMA inhibitor which is frequently used as a competitor for PSMA-targeted tracers [123]. It was shown that administration of 2-PMPA decreased binding of PSMA-targeted tracers in the kidneys in a dose dependent manner, but at the expense of (to a lesser extent) decreased uptake in the tumor $[31,113,116]$. In line of this research it has been reported that slightly decreasing the molar activity, or the using low concentrations of unlabeled or non-radioactive labeled tracers can positively influence the tumor-to-kidney-ratio and warrants further research $[113,124,125]$. In order to specifically shield the kidneys and salivary glands from PSMA-TRT with 2-PMPA, a novel prodrug (e.g., Tris-POC-2-PMPA) has been proposed which is suggested to specifically bind in non-malignant tissues and hence reduce toxicity [126]. Further (pre)clinical research is needed to investigate the potential of this compound to protect the salivary glands and kidneys without affecting tumor uptake.

Finally, a strategy to reduce renal uptake of PSMA-targeted tracers is the use of mannitol, which can act as an osmotic diuretic in the PSMA expressing proximal tubules of the kidneys. Because mannitol promotes diuresis, reabsorption of the PSMA-targeting tracers may decrease, which is hypothesized to decrease overall renal uptake [127]. However, first clinical imaging studies revealed that mannitol did not show a significant effect on the uptake of PSMA-specific tracers $[108,127]$.

To summarize, it has become evident that there is an urgent need for PSMA-specific renal and salivary gland protection for PCa patients receiving PSMA-TRT. The lack of an adequate preclinical research model to reflect the situation in humans is a major challenge. Increasing evidence suggests that besides PSMA-specific binding, also non-specific binding of PSMA may play a role in the uptake of PSMA-targeting tracers in the salivary glands. Further investigations are needed to identify a compound that is able to selectively block both specific and/or non-specific binding of PSMA tracers in the salivary glands and the kidneys to improve safety without affecting tumor uptake.

\section{Concluding Remarks}

PSMA-targeting tracers have made a steep introduction into clinical staging of PCa and a fast implementation towards PSMA-TRT. This fast clinical integration, however, requires preclinical research to assure optimal use with maximal safety. Preclinical PSMA-TRT studies are able to test and compare a wide range of methods in a high throughput manner in order to ultimately improving PSMA-TRT therapeutic effectiveness while simultaneously decreasing the uptake in the healthy PSMA-expressing kidneys and salivary glands. Improving already existing PSMA-targeting tracers, creating bi-ligands, 
experimenting with various radionuclides, enhancing therapeutic effects by using radio-sensitizers, and looking for compounds that selectively block the healthy PMSA-expressing organs from PSMA-TRT are major focus points in PSMA preclinical research. The preclinical studies discussed here and ongoing preclinical research will inevitably determine the future of PSMA-TRT in the clinic.

Author Contributions: Conceptualization by E.A.M.R., M.d.J. and J.N.; E.A.M.R. wrote the manuscript; M.d.J., J.N and W.M.v.W. contributed with comments to reach the final version; all authors read and approved the final manuscript.

Funding: This study was supported by the Dutch Cancer Society (grant number 10317).

Conflicts of Interest: The authors declare no conflict of interest.

\section{References}

1. Ferlay, J.; Colombet, M.; Soerjomataram, I.; Dyba, T.; Randi, G.; Bettio, M.; Gavin, A.; Visser, O.; Bray, F. Cancer incidence and mortality patterns in Europe: Estimates for 40 countries and 25 major cancers in 2018. Eur. J. Cancer 2018, 103, 356-387. [CrossRef] [PubMed]

2. Siegel, R.L.; Miller, K.D.; Jemal, A. Cancer statistics, 2019. CA Cancer J. Clin. 2019, 69, 7-34. [CrossRef] [PubMed]

3. Parker, C.; Gillessen, S.; Heidenreich, A.; Horwich, A.; Committee, E.G. Cancer of the prostate: ESMO Clinical Practice Guidelines for diagnosis, treatment and follow-up. Ann. Oncol. 2015, 26 (Suppl. 5), v69-v77. [CrossRef] [PubMed]

4. Zaman, M.U.; Fatima, N.; Zaman, A.; Sajid, M.; Zaman, U.; Zaman, S. Diagnostic challenges in prostate cancer and ${ }^{68} \mathrm{Ga}$-PSMA PET Imaging: A game changer? Asian Pac. J. Cancer Prev. 2017, 18, 2625-2628. [PubMed]

5. Horoszewicz, J.S.; Kawinski, E.; Murphy, G.P. Monoclonal antibodies to a new antigenic marker in epithelial prostatic cells and serum of prostatic cancer patients. Anticancer Res. 1987, 7, 927-935. [PubMed]

6. Kawakami, M.; Nakayama, J. Enhanced expression of prostate-specific membrane antigen gene in prostate cancer as revealed by in situ hybridization. Cancer Res. 1997, 57, 2321-2324. [PubMed]

7. Bostwick, D.G.; Pacelli, A.; Blute, M.; Roche, P.; Murphy, G.P. Prostate specific membrane antigen expression in prostatic intraepithelial neoplasia and adenocarcinoma: A study of 184 cases. Cancer 1998, 82, 2256-2261. [CrossRef]

8. Silver, D.A.; Pellicer, I.; Fair, W.R.; Heston, W.D.; Cordon-Cardo, C. Prostate-specific membrane antigen expression in normal and malignant human tissues. Clin. Cancer Res. 1997, 3, 81-85.

9. Bouchelouche, K.; Choyke, P.L.; Capala, J. Prostate specific membrane antigen-A target for imaging and therapy with radionuclides. Discov. Med. 2010, 9, 55-61.

10. Wright, G.L., Jr.; Haley, C.; Beckett, M.L.; Schellhammer, P.F. Expression of prostate-specific membrane antigen in normal, benign, and malignant prostate tissues. Urol. Oncol. 1995, 1, 18-28. [CrossRef]

11. Backhaus, P.; Noto, B.; Avramovic, N.; Grubert, L.S.; Huss, S.; Bogemann, M.; Stegger, L.; Weckesser, M.; Schafers, M.; Rahbar, K. Targeting PSMA by radioligands in non-prostate disease-current status and future perspectives. Eur. J. Nucl. Med. Mol. Imaging 2018, 45, 860-877. [CrossRef] [PubMed]

12. Kratochwil, C.; Bruchertseifer, F.; Rathke, H.; Bronzel, M.; Apostolidis, C.; Weichert, W.; Haberkorn, U.; Giesel, F.L.; Morgenstern, A. Targeted $\alpha$-therapy of metastatic castration-resistant prostate cancer with ${ }^{225}$ Ac-PSMA-617: Dosimetry Estimate and empiric dose finding. J. Nucl. Med. 2017, 58, 1624-1631. [CrossRef] [PubMed]

13. Virgolini, I.; Decristoforo, C.; Haug, A.; Fanti, S.; Uprimny, C. Current status of theranostics in prostate cancer. Eur. J. Nucl. Med. Mol. Imaging 2018, 45, 471-495. [CrossRef] [PubMed]

14. Heston, W.D. [Significance of prostate-specific membrane antigen (PSMA). A neurocarboxypeptidase and membrane folate hydrolase]. Bedeutung des prostataspezifischen Membranantigens (PSMA). Eine Neurocarboxypeptidase und Membran-Folat-Hydrolase. Urol. A 1996, 35, 400-407. [CrossRef]

15. Wustemann, T.; Haberkorn, U.; Babich, J.; Mier, W. Targeting prostate cancer: Prostate-specific membrane antigen based diagnosis and therapy. Med. Res. Rev. 2019, 39, 40-69. [CrossRef]

16. Teo, M.Y.; Morris, M.J. Prostate-Specific membrane antigen-directed therapy for metastatic castration-resistant prostate cancer. Cancer J. 2016, 22, 347-352. [CrossRef] 
17. Cimadamore, A.; Cheng, M.; Santoni, M.; Lopez-Beltran, A.; Battelli, N.; Massari, F.; Galosi, A.B.; Scarpelli, M.; Montironi, R. New prostate cancer targets for diagnosis, imaging, and therapy: Focus on Prostate-specific membrane antigen. Front. Oncol. 2018, 8, 653. [CrossRef]

18. Pillai, M.R.A.; Nanabala, R.; Joy, A.; Sasikumar, A.; Russ Knapp, F.F. Radiolabeled enzyme inhibitors and binding agents targeting PSMA: Effective theranostic tools for imaging and therapy of prostate cancer. Nucl. Med. Biol. 2016, 43, 692-720. [CrossRef]

19. Arsenault, F.; Beauregard, J.M.; Pouliot, F. Prostate-specific membrane antigen for prostate cancer theranostics: From imaging to targeted therapy. Curr. Opin. Support. Palliat. Care 2018, 12, 359-365. [CrossRef]

20. Eiber, M.; Fendler, W.P.; Rowe, S.P.; Calais, J.; Hofman, M.S.; Maurer, T.; Schwarzenboeck, S.M.; Kratowchil, C.; Herrmann, K.; Giesel, F.L. Prostate-specific membrane antigen ligands for imaging and therapy. J. Nucl. Med. 2017, 58 (Suppl. 2), 67s-76s. [CrossRef]

21. Afshar-Oromieh, A.; Babich, J.W.; Kratochwil, C.; Giesel, F.L.; Eisenhut, M.; Kopka, K.; Haberkorn, U. The rise of PSMA Ligands for diagnosis and therapy of prostate cancer. J. Nucl. Med. 2016, 57 (Suppl. 3), 79S-89S. [CrossRef] [PubMed]

22. Kopka, K.; Benesova, M.; Barinka, C.; Haberkorn, U.; Babich, J. Glu-ureido-based inhibitors of prostate-specific membrane antigen: Lessons learned during the development of a novel class of low-molecular-weight theranostic radiotracers. J. Nucl. Med. 2017, 58 (Suppl. 2), 17S-26S. [CrossRef] [PubMed]

23. Diao, W.; Cai, H.; Chen, L.; Jin, X.; Liao, X.; Jia, Z. Recent advances in prostate-specific membrane antigen-based radiopharmaceuticals. Curr. Top. Med. Chem. 2019, 19, 33-56. [CrossRef] [PubMed]

24. Evans, J.D.; et al. Prostate cancer-specific PET radiotracers: A review on the clinical utility in recurrent disease. Pract. Radiat. Oncol. 2018, 8, 28-39. [CrossRef]

25. Wester, H.J.; Schottelius, M. PSMA-targeted radiopharmaceuticals for imaging and therapy. Semin. Nucl. Med. 2019, 49, 302-312. [CrossRef]

26. Benesova, M.; Schafer, M.; Bauder-Wust, U.; Afshar-Oromieh, A.; Kratochwil, C.; Mier, W.; Haberkorn, U.; Kopka, K.; Eder, M. Preclinical Evaluation of a tailor-made DOTA-conjugated PSMA inhibitor with optimized linker moiety for imaging and endoradiotherapy of prostate cancer. J. Nucl. Med. 2015, 56, 914-920. [CrossRef]

27. Hofman, M.S.; Violet, J.; Hicks, R.J.; Ferdinandus, J.; Thang, S.P.; Akhurst, T.; Iravani, A.; Kong, G.; Ravi Kumar, A.; Murphy, D.G.; et al. [ $\left.{ }^{177} \mathrm{Lu}\right]-P S M A-617$ radionuclide treatment in patients with metastatic castration-resistant prostate cancer (LuPSMA trial): A single-centre, single-arm, phase 2 study. Lancet Oncol. 2018, 19, 825-833. [CrossRef]

28. Sathekge, M.; Bruchertseifer, F.; Knoesen, O.; Reyneke, F.; Lawal, I.; Lengana, T.; Davis, C.; Mahapane, J.; Corbett, C.; Vorster, M.; et al. ${ }^{225}$ Ac-PSMA-617 in chemotherapy-naive patients with advanced prostate cancer: A pilot study. Eur. J. Nucl. Med. Mol. Imaging 2019, 46, 129-138. [CrossRef]

29. Weineisen, M.; Schottelius, M.; Simecek, J.; Baum, R.P.; Yildiz, A.; Beykan, S.; Kulkarni, H.R.; Lassmann, M.; Klette, I.; Eiber, M.; et al. ${ }^{68} \mathrm{Ga}$ - and ${ }^{177}$ Lu-labeled PSMA I\&T: Optimization of a PSMA-targeted theranostic concept and first proof-of-concept human studies. J. Nucl. Med. 2015, 56, 1169-1176.

30. Heck, M.M.; Retz, M.; D'Alessandria, C.; Rauscher, I.; Scheidhauer, K.; Maurer, T.; Storz, E.; Janssen, F.; Schottelius, M.; Wester, H.J.; et al. Systemic radioligand therapy with ${ }^{177} \mathrm{Lu}$ labeled prostate specific membrane antigen ligand for imaging and therapy in patients with metastatic castration resistant prostate cancer. J. Urol. 2016, 196, 382-391. [CrossRef]

31. Hillier, S.M.; Maresca, K.P.; Femia, F.J.; Marquis, J.C.; Foss, C.A.; Nguyen, N.; Zimmerman, C.N.; Barrett, J.A.; Eckelman, W.C.; Pomper, M.G.; et al. Preclinical evaluation of novel glutamate-urea-lysine analogues that target prostate-specific membrane antigen as molecular imaging pharmaceuticals for prostate cancer. Cancer Res. 2009, 69, 6932-6940. [CrossRef] [PubMed]

32. Afshar-Oromieh, A.; Haberkorn, U.; Zechmann, C.; Armor, T.; Mier, W.; Spohn, F.; Debus, N.; Holland-Letz, T.; Babich, J.; Kratochwil, C. Repeated PSMA-targeting radioligand therapy of metastatic prostate cancer with ${ }^{131}$ I-MIP-1095. Eur. J. Nucl. Med. Mol. Imaging 2017, 44, 950-959. [CrossRef] [PubMed]

33. Barrett, J.A.; Coleman, R.E.; Goldsmith, S.J.; Vallabhajosula, S.; Petry, N.A.; Cho, S.; Armor, T.; Stubbs, J.B.; Maresca, K.P.; Stabin, M.G.; et al. First-in-man evaluation of 2 high-affinity PSMA-avid small molecules for imaging prostate cancer. J. Nucl. Med. 2013, 54, 380-387. [CrossRef] [PubMed] 
34. Hillier, S.M.; Maresca, K.P.; Lu, G.; Merkin, R.D.; Marquis, J.C.; Zimmerman, C.N.; Eckelman, W.C.; Joyal, J.L.; Babich, J.W. ${ }^{99 \mathrm{~m}} \mathrm{Tc}$-labeled small-molecule inhibitors of prostate-specific membrane antigen for molecular imaging of prostate cancer. J. Nucl. Med. 2013, 54, 1369-1376. [CrossRef] [PubMed]

35. Schmidkonz, C.; Hollweg, C.; Beck, M.; Reinfelder, J.; Goetz, T.I.; Sanders, J.C.; Schmidt, D.; Prante, O.; Bauerle, T.; Cavallaro, A.; et al. ${ }^{99 \mathrm{~m}}$ Tc-MIP-1404-SPECT/CT for the detection of PSMA-positive lesions in 225 patients with biochemical recurrence of prostate cancer. Prostate 2018, 78, 54-63. [CrossRef] [PubMed]

36. Robu, S.; Schottelius, M.; Eiber, M.; Maurer, T.; Gschwend, J.; Schwaiger, M.; Wester, H.J. Preclinical evaluation and first patient application of ${ }^{99} \mathrm{~m}$ Tc-PSMA-I\&S for SPECT imaging and radioguided surgery in prostate cancer. J. Nucl. Med. 2017, 58, 235-242. [PubMed]

37. Choy, C.J.; Ling, X.; Geruntho, J.J.; Beyer, S.K.; Latoche, J.D.; Langton-Webster, B.; Anderson, C.J.; Berkman, C.E. ${ }^{177}$ Lu-Labeled phosphoramidate-based PSMA inhibitors: The effect of an albumin binder on biodistribution and therapeutic efficacy in prostate tumor-bearing mice. Theranostics 2017, 7, 1928-1939. [CrossRef]

38. Kelly, J.M.; Amor-Coarasa, A.; Nikolopoulou, A.; Wustemann, T.; Barelli, P.; Kim, D.; Williams, C., Jr.; Zheng, X.; Bi, C.; Hu, B.; et al. Dual-target binding ligands with modulated pharmacokinetics for endoradiotherapy of prostate cancer. J. Nucl. Med. 2017, 58, 1442-1449. [CrossRef]

39. Kiess, A.P.; Minn, I.; Chen, Y.; Hobbs, R.; Sgouros, G.; Mease, R.C.; Pullambhatla, M.; Shen, C.J.; Foss, C.A.; Pomper, M.G. Auger radiopharmaceutical therapy targeting prostate-specific membrane antigen. J. Nucl. Med. 2015, 56, 1401-1407. [CrossRef]

40. Chakravarty, R.; Siamof, C.M.; Dash, A.; Cai, W. Targeted $\alpha$-therapy of prostate cancer using radiolabeled PSMA inhibitors: A game changer in nuclear medicine. Am. J. Nucl. Med. Mol. Imaging 2018, 8, 247-267.

41. Kulkarni, H.R.; Singh, A.; Langbein, T.; Schuchardt, C.; Mueller, D.; Zhang, J.; Lehmann, C.; Baum, R.P. Theranostics of prostate cancer: From molecular imaging to precision molecular radiotherapy targeting the prostate specific membrane antigen. Br. J. Radiol. 2018, 91, 20180308. [CrossRef] [PubMed]

42. Huang, S.S.; Heston, W.D.W. should low molecular weight PSMA targeted ligands get bigger and use albumin ligands for PSMA targeting? Theranostics 2017, 7, 1940-1941. [CrossRef] [PubMed]

43. Dennis, M.S.; Zhang, M.; Meng, Y.G.; Kadkhodayan, M.; Kirchhofer, D.; Combs, D.; Damico, L.A. Albumin binding as a general strategy for improving the pharmacokinetics of proteins. J. Biol. Chem. 2002, 277, 35035-35043. [CrossRef] [PubMed]

44. Wang, Y.; Wang, S.; Huang, M. Structure and enzymatic activities of human serum albumin. Curr. Pharm. Des. 2015, 21, 1831-1836. [CrossRef]

45. Infusino, I.; Panteghini, M. Serum albumin: Accuracy and clinical use. Clin. Chim. Acta 2013, 419, 15-18. [CrossRef]

46. Wang, Z.; Jacobson, O.; Tian, R.; Mease, R.C.; Kiesewetter, D.O.; Niu, G.; Pomper, M.G.; Chen, X. Radioligand therapy of prostate cancer with a long-lasting prostate-specific membrane antigen targeting agent ${ }^{90}$ Y-DOTA-EB-MCG. Bioconjug. Chem. 2018, 29, 2309-2315. [CrossRef]

47. Merlot, A.M.; Kalinowski, D.S.; Richardson, D.R. Unraveling the mysteries of serum albumin-more than just a serum protein. Front. Physiol. 2014, 5, 299. [CrossRef]

48. Muller, C.; Struthers, H.; Winiger, C.; Zhernosekov, K.; Schibli, R. DOTA conjugate with an albumin-binding entity enables the first folic acid-targeted 177Lu-radionuclide tumor therapy in mice. J. Nucl. Med. 2013, 54, 124-131. [CrossRef]

49. Kelly, J.; Amor-Coarasa, A.; Ponnala, S.; Nikolopoulou, A.; Williams, C., Jr.; Schlyer, D.; Zhao, Y.; Kim, D.; Babich, J.W. Trifunctional PSMA-targeting constructs for prostate cancer with unprecedented localization to LNCaP tumors. Eur. J. Nucl. Med. Mol. Imaging 2018, 45, 1841-1851. [CrossRef]

50. Benesova, M.; Umbricht, C.A.; Schibli, R.; Muller, C. Albumin-binding PSMA ligands: Optimization of the tissue distribution profile. Mol. Pharm. 2018, 15, 934-946. [CrossRef]

51. Kuo, H.T.; Merkens, H.; Zhang, Z.; Uribe, C.F.; Lau, J.; Zhang, C.; Colpo, N.; Lin, K.S.; Benard, F. Enhancing treatment efficacy of ${ }^{177} \mathrm{Lu}$-PSMA-617 with the conjugation of an albumin-binding motif: Preclinical dosimetry and endoradiotherapy studies. Mol. Pharm. 2018, 15, 5183-5191. [CrossRef] [PubMed]

52. Umbricht, C.A.; Benesova, M.; Schibli, R.; Muller, C. Preclinical development of novel PSMA-targeting radioligands: Modulation of albumin-binding properties to improve prostate cancer therapy. Mol. Pharm. 2018, 15, 2297-2306. [CrossRef] [PubMed] 
53. Kelly, J.M.; Amor-Coarasa, A.; Ponnala, S.; Nikolopoulou, A.; Williams, C., Jr.; DiMagno, S.G.; Babich, J. Albumin-binding PSMA ligands: Implications for expanding the therapeutic window. J. Nucl. Med. 2018, 60, 656-663. [CrossRef] [PubMed]

54. Kelly, J.M.; Amor-Coarasa, A.; Ponnala, S.; Nikolopoulou, A.; Williams, C., Jr.; Thiele, N.A.; Schlyer, D.; Wilson, J.J.; DiMagno, S.G.; Babich, J.W. A single dose of ${ }^{225}$ Ac-RPS-074 induces a complete tumor response in a LNCaP xenograft model. J. Nucl. Med. 2018, 60, 649-655. [CrossRef] [PubMed]

55. Benesova, M.; Bauder-Wust, U.; Schafer, M.; Klika, K.D.; Mier, W.; Haberkorn, U.; Kopka, K.; Eder, M. Linker Modification strategies to control. the prostate-specific membrane antigen (PSMA)-Targeting and pharmacokinetic properties of DOTA-conjugated PSMA inhibitors. J. Med. Chem. 2016, 59, 1761-1775. [CrossRef]

56. Huang, S.S.; Wang, X.; Zhang, Y.; Doke, A.; DiFilippo, F.P.; Heston, W.D. Improving the biodistribution of PSMA-targeting tracers with a highly negatively charged linker. Prostate 2014, 74, 702-713. [CrossRef]

57. Wustemann, T.; Bauder-Wust, U.; Schafer, M.; Eder, M.; Benesova, M.; Leotta, K.; Kratochwil, C.; Haberkorn, U.; Kopka, K.; Mier, W. Design of internalizing PSMA-specific glu-ureido-based radiotherapeuticals. Theranostics 2016, 6, 1085-1095. [CrossRef]

58. Schmidt, A.; Wirtz, M.; Farber, S.F.; Osl, T.; Beck, R.; Schottelius, M.; Schwaiger, M.; Wester, H.J. Effect of carbohydration on the theranostic tracer PSMA I\&T. ACS Omega 2018, 3, 8278-8287.

59. Kuo, H.T.; Pan, J.; Zhang, Z.; Lau, J.; Merkens, H.; Zhang, C.; Colpo, N.; Lin, K.S.; Benard, F. Effects of Linker modification on tumor-to-kidney contrast of ${ }^{68} \mathrm{Ga}$-labeled PSMA-targeted imaging probes. Mol. Pharm. 2018, 15, 3502-3511. [CrossRef]

60. Ray Banerjee, S.; Chen, Z.; Pullambhatla, M.; Lisok, A.; Chen, J.; Mease, R.C.; Pomper, M.G. Preclinical comparative study of ${ }^{68} \mathrm{Ga}$-labeled DOTA, NOTA, and HBED-CC chelated Radiotracers for targeting PSMA. Bioconjug. Chem. 2016, 27, 1447-1455. [CrossRef]

61. Ray Banerjee, S.; Pullambhatla, M.; Foss, C.A.; Falk, A.; Byun, Y.; Nimmagadda, S.; Mease, R.C.; Pomper, M.G. Effect of chelators on the pharmacokinetics of ${ }^{99 \mathrm{~m}} \mathrm{Tc}$-labeled imaging agents for the prostate-specific membrane antigen (PSMA). J. Med. Chem. 2013, 56, 6108-6121. [CrossRef] [PubMed]

62. Wurzer, A.; Seidl, C.; Morgenstern, A.; Bruchertseifer, F.; Schwaiger, M.; Wester, H.J.; Notni, J. Dual-nuclide Radiopharmaceuticals for positron emission tomography based dosimetry in radiotherapy. Chemistry 2018, 24, 547-550. [CrossRef] [PubMed]

63. Lim, J.; Guan, B.; Nham, K.; Hao, G.; Sun, X.; Simanek, E.E. Tumor uptake of triazine dendrimers decorated with four, sixteen, and sixty-four PSMA-targeted ligands: Passive versus active tumor targeting. Biomolecules 2019, 9, 421. [CrossRef] [PubMed]

64. Schafer, M.; Bauder-Wust, U.; Leotta, K.; Zoller, F.; Mier, W.; Haberkorn, U.; Eisenhut, M.; Eder, M. A dimerized urea-based inhibitor of the prostate-specific membrane antigen for ${ }^{68} \mathrm{Ga}$-PET imaging of prostate cancer. EJNMMI Res. 2012, 2, 23. [CrossRef]

65. Liolios, C.; Schafer, M.; Haberkorn, U.; Eder, M.; Kopka, K. Novel bispecific PSMA/GRPr targeting radioligands with optimized pharmacokinetics for improved PET imaging of prostate cancer. Bioconjug. Chem. 2016, 27, 737-751. [CrossRef] [PubMed]

66. Eder, M.; Schafer, M.; Bauder-Wust, U.; Haberkorn, U.; Eisenhut, M.; Kopka, K. Preclinical evaluation of a bispecific low-molecular heterodimer targeting both PSMA and GRPR for improved PET imaging and therapy of prostate cancer. Prostate 2014, 74, 659-668. [CrossRef]

67. Wu, Q.; Parry, G. Hepsin and prostate cancer. Front. Biosci. 2007, 12, 5052-5059. [CrossRef]

68. Subedi, M.; Minn, I.; Chen, J.; Kim, Y.; Ok, K.; Jung, Y.W.; Pomper, M.G.; Byun, Y. Design, synthesis and biological evaluation of PSMA/hepsin-targeted heterobivalent ligands. Eur. J. Med. Chem. 2016, 118, $208-218$. [CrossRef]

69. Shallal, H.M.; Minn, I.; Banerjee, S.R.; Lisok, A.; Mease, R.C.; Pomper, M.G. Heterobivalent agents targeting PSMA and integrin- $\alpha_{v} \beta_{3}$. Bioconjug. Chem. 2014, 25, 393-405. [CrossRef]

70. Escudero-Castellanos, A.; Ocampo-Garcia, B.; Ferro-Flores, G.; Santos-Cuevas, C.; Morales-Avila, E.; Luna-Gutierrez, M.; Isaac-Olive, K. Synthesis and preclinical evaluation of the ${ }^{177}$ Lu-DOTA-PSMA(inhibitor)-Lys3bombesin heterodimer designed as a radiotheranostic probe for prostate cancer. Nucl. Med. Commun. 2019, 40, 278-286. [CrossRef]

71. Iagaru, A. Will GRPR compete with PSMA as a target in prostate cancer? J. Nucl. Med. 2017, 58, $1883-1884$. [CrossRef] [PubMed] 
72. Ananias, H.J.; van den Heuvel, M.C.; Helfrich, W.; de Jong, I.J. Expression of the gastrin-releasing peptide receptor, the prostate stem cell antigen and the prostate-specific membrane antigen in lymph node and bone metastases of prostate cancer. Prostate 2009, 69, 1101-1108. [CrossRef] [PubMed]

73. Bandari, R.P.; Jiang, Z.; Reynolds, T.S.; Bernskoetter, N.E.; Szczodroski, A.F.; Bassuner, K.J.; Kirkpatrick, D.L.; Rold, T.L.; Sieckman, G.L.; Hoffman, T.J.; et al. Synthesis and biological evaluation of copper-64 radiolabeled [DUPA-6-Ahx-(NODAGA)-5-Ava-BBN(7-14) $\mathrm{NH}_{2}$ ], a novel bivalent targeting vector having affinity for two distinct biomarkers (GRPr/PSMA) of prostate cancer. Nucl. Med. Biol. 2014, 41, 355-363. [CrossRef] [PubMed]

74. Abouzayed, A.; Yim, C.B.; Mitran, B.; Rinne, S.S.; Tolmachev, V.; Larhed, M.; Rosenstrom, U.; Orlova, A. Synthesis and preclinical evaluation of radio-iodinated GRPR/PSMA bispecific heterodimers for the theranostics application in prostate cancer. Pharmaceutics 2019, 11, 358. [CrossRef]

75. Kassis, A.I. Therapeutic radionuclides: Biophysical and radiobiologic principles. Semin. Nucl. Med. 2008, 38, 358-366. [CrossRef]

76. Rahbar, K.; Ahmadzadehfar, H.; Kratochwil, C.; Haberkorn, U.; Schafers, M.; Essler, M.; Baum, R.P.; Kulkarni, H.R.; Schmidt, M.; Drzezga, A.; et al. German Multicenter study investigating ${ }^{177}$ Lu-PSMA-617 radioligand therapy in advanced prostate cancer patients. J. Nucl. Med. 2017, 58, 85-90. [CrossRef]

77. Kratochwil, C.; Giesel, F.L.; Stefanova, M.; Benesova, M.; Bronzel, M.; Afshar-Oromieh, A.; Mier, W.; Eder, M.; Kopka, K.; Haberkorn, U. PSMA-Targeted radionuclide therapy of metastatic castration-resistant prostate cancer with ${ }^{177}$ Lu-labeled PSMA-617. J. Nucl. Med. 2016, 57, 1170-1176. [CrossRef]

78. Champion, C.; Quinto, M.A.; Morgat, C.; Zanotti-Fregonara, P.; Hindie, E. Comparison between 117117, ${ }^{67} \mathrm{Cu},{ }^{47} \mathrm{Sc}$ and ${ }^{161} \mathrm{~Tb}$, with 117117. Theranostics 2016, 6, 1611-1618. [CrossRef]

79. Muller, C.; Umbricht, C.A.; Gracheva, N.; Tschan, V.J.; Pellegrini, G.; Bernhardt, P.; Zeevaart, J.R.; Koster, U.; Schibli, R.; van der Meulen, N.P. Terbium-161 for PSMA-targeted radionuclide therapy of prostate cancer. Eur. J. Nucl. Med. Mol. Imaging 2019, 46, 1919-1930. [CrossRef]

80. Nonnekens, J.; Chatalic, K.L.; Molkenboer-Kuenen, J.D.; Beerens, C.E.; Bruchertseifer, F.; Morgenstern, A.; Veldhoven-Zweistra, J.; Schottelius, M.; Wester, H.J.; van Gent, D.C.; et al. ${ }^{213}$ Bi-labeled prostate-specific membrane antigen-targeting agents induce DNA double-strand breaks in prostate cancer xenografts. Cancer Biother. Radiopharm. 2017, 32, 67-73. [CrossRef]

81. Graf, F.; Fahrer, J.; Maus, S.; Morgenstern, A.; Bruchertseifer, F.; Venkatachalam, S.; Fottner, C.; Weber, M.M.; Huelsenbeck, J.; Schreckenberger, M.; et al. DNA double strand breaks as predictor of efficacy of the alpha-particle emitter Ac-225 and the electron emitter Lu-177 for somatostatin receptor targeted radiotherapy. PLoS ONE 2014, 9, e88239. [CrossRef] [PubMed]

82. Zustovich, F.; Barsanti, R. Targeted $\alpha$ therapies for the treatment of bone metastases. Int. J. Mol. Sci. 2017, 19, 74. [CrossRef] [PubMed]

83. Kiess, A.P.; Minn, I.; Vaidyanathan, G.; Hobbs, R.F.; Josefsson, A.; Shen, C.; Brummet, M.; Chen, Y.; Choi, J.; Koumarianou, E.; et al. (2S)-2-(3-(1-Carboxy-5-(4-211 At-Astatobenzamido)Pentyl)Ureido)-pentanedioic acid for PSMA-targeted $\alpha$-particle radiopharmaceutical therapy. J. Nucl. Med. 2016, 57, 1569-1575. [CrossRef] [PubMed]

84. Kratochwil, C.; Bruchertseifer, F.; Rathke, H.; Hohenfellner, M.; Giesel, F.L.; Haberkorn, U.; Morgenstern, A. Targeted $\alpha$-therapy of metastatic castration-resistant prostate cancer with ${ }^{225}$ Ac-PSMA-617: Swimmer-plot analysis suggests efficacy regarding duration of tumor control. J. Nucl. Med. 2018, 59, 795-802. [CrossRef]

85. Dos Santos, J.C.; Schafer, M.; Bauder-Wust, U.; Lehnert, W.; Leotta, K.; Morgenstern, A.; Kopka, K.; Haberkorn, U.; Mier, W.; Kratochwil, C. Development and dosimetry of ${ }^{203} \mathrm{~Pb} /{ }^{212} \mathrm{~Pb}$-labelled PSMA ligands: Bringing "the lead" into PSMA-targeted alpha therapy? Eur. J. Nucl. Med. Mol. Imaging 2019, 46, 1081-1091. [CrossRef] [PubMed]

86. Ray Banerjee, S.; Minn, I.L.; Kumar, V.; Josefsson, A.; Lisok, A.; Brummet, M.; Chen, J.; Kiess, A.; Baidoo, K.; Brayton, C. Preclinical evaluation of ${ }^{203 / 212} \mathrm{~Pb}$-labeled low-molecular-weight compounds for targeted radiopharmaceutical therapy of prostate cancer. J. Nucl. Med. 2019. [CrossRef]

87. Malcolm, J.; Falzone, N.; Lee, B.Q.; Vallis, K.A. Targeted radionuclide therapy: New advances for improvement of patient management and response. Cancers 2019, 11, 268. [CrossRef]

88. Gill, M.R.; Falzone, N.; Du, Y.; Vallis, K.A. Targeted radionuclide therapy in combined-modality regimens. Lancet Oncol. 2017, 18, e414-e423. [CrossRef]

89. Wardman, P. Chemical radiosensitizers for use in radiotherapy. Clin. Oncol. 2007, 19, 397-417. [CrossRef] 
90. Palacios, D.A.; Miyake, M.; Rosser, C.J. Radiosensitization in prostate cancer: Mechanisms and targets. BMC Urol. 2013, 13, 4. [CrossRef]

91. Tesson, M.; Rae, C.; Nixon, C.; Babich, J.W.; Mairs, R.J. Preliminary evaluation of prostate-targeted radiotherapy using ${ }^{131} \mathrm{I}-\mathrm{MIP}-1095$ in combination with radiosensitising chemotherapeutic drugs. J. Pharm. Pharmacol. 2016, 68, 912-921. [CrossRef] [PubMed]

92. Perlmutter, M.A.; Lepor, H. Androgen deprivation therapy in the treatment of advanced prostate cancer. Rev. Urol. 2007, 9 (Suppl. 1), S3-S8. [PubMed]

93. Mottet, N.; Bellmunt, J.; Bolla, M.; Briers, E.; Cumberbatch, M.G.; De Santis, M.; Fossati, N.; Gross, T.; Henry, A.M.; Joniau, S.; et al. EAU-ESTRO-SIOG Guidelines on prostate cancer. Part. 1: Screening, diagnosis, and local treatment with curative intent. Eur. Urol. 2017, 71, 618-629. [CrossRef] [PubMed]

94. Mengdi, Q.; Almasan, A.; Gurkan-Cavusoglu, E. Computational analysis of androgen receptor dependent radiosensitivity in prostate cancer. In Proceedings of the 38th Annual International Conference of the IEEE Engineering in Medicine and Biology Society (EMBC), Lake Buena Vista, FL, USA, 17-20 August 2016; pp. 1426-1429.

95. Schmidt-Hansen, M.; Hoskin, P.; Kirkbride, P.; Hasler, E.; Bromham, N. Hormone and radiotherapy versus hormone or radiotherapy alone for non-metastatic prostate cancer: A systematic review with meta-analyses. Clin. Oncol. 2014, 26, e21-e46. [CrossRef]

96. Jones, C.U.; et al. Radiotherapy and short-term androgen deprivation for localized prostate cancer. N. Engl. J. Med. 2011, 365, 107-118. [CrossRef]

97. D'Amico, A.V.; Manola, J.; Loffredo, M.; Renshaw, A.A.; DellaCroce, A.; Kantoff, P.W. 6-month androgen suppression plus radiation therapy vs. radiation therapy alone for patients with clinically localized prostate cancer: A randomized controlled trial. JAMA 2004, 292, 821-827. [CrossRef]

98. Goodwin, J.F.; Schiewer, M.J.; Dean, J.L.; Schrecengost, R.S.; de Leeuw, R.; Han, S.; Ma, T.; Den, R.B.; Dicker, A.P.; Feng, F.Y.; et al. A hormone-DNA repair circuit governs the response to genotoxic insult. Cancer Discov. 2013, 3, 1254-1271. [CrossRef]

99. Sekhar, K.R.; Wang, J.; Freeman, M.L.; Kirschner, A.N. Radiosensitization by enzalutamide for human prostate cancer is mediated through the DNA damage repair pathway. PLoS ONE 2019, 14, e0214670. [CrossRef]

100. Chou, F.J.; Chen, Y.; Chen, D.; Niu, Y.; Li, G.; Keng, P.; Yeh, S.; Chang, C. Preclinical study using androgen receptor (AR) degradation enhancer to increase radiotherapy efficacy via targeting radiation-increased $A R$ to better suppress prostate cancer progression. EBioMedicine 2019, 40, 504-516. [CrossRef]

101. Meller, B.; Bremmer, F.; Sahlmann, C.O.; Hijazi, S.; Bouter, C.; Trojan, L.; Meller, J.; Thelen, P. Alterations in androgen deprivation enhanced prostate-specific membrane antigen (PSMA) expression in prostate cancer cells as a target for diagnostics and therapy. EJNMMI Res. 2015, 5, 66. [CrossRef]

102. Leitsmann, C.; Thelen, P.; Schmid, M.; Meller, J.; Sahlmann, C.O.; Meller, B.; Trojan, L.; Strauss, A. Enhancing PSMA-uptake with androgen deprivation therapy-A new way to detect prostate cancer metastases? Int. Braz. J. Urol. 2019, 45, 459-467. [CrossRef] [PubMed]

103. Wright, G.L., Jr.; Grob, B.M.; Haley, C.; Grossman, K.; Newhall, K.; Petrylak, D.; Troyer, J.; Konchuba, A.; Schellhammer, P.F.; Moriarty, R. Upregulation of prostate-specific membrane antigen after androgen-deprivation therapy. Urology 1996, 48, 326-334. [CrossRef]

104. Liu, T.; Wu, L.Y.; Fulton, M.D.; Johnson, J.M.; Berkman, C.E. Prolonged androgen deprivation leads to downregulation of androgen receptor and prostate-specific membrane antigen in prostate cancer cells. Int. J. Oncol. 2012, 41, 2087-2092. [CrossRef] [PubMed]

105. Chang, S.S.; Reuter, V.E.; Heston, W.D.; Hutchinson, B.; Grauer, L.S.; Gaudin, P.B. Short term neoadjuvant androgen deprivation therapy does not affect prostate specific membrane antigen expression in prostate tissues. Cancer 2000, 88, 407-415. [CrossRef]

106. Luckerath, K.; Wei, L.; Fendler, W.P.; Evans-Axelsson, S.; Stuparu, A.D.; Slavik, R.; Mona, C.E.; Calais, J.; Rettig, M.; Reiter, R.E.; et al. Preclinical evaluation of PSMA expression in response to androgen receptor blockade for theranostics in prostate cancer. EJNMMI Res. 2018, 8, 96. [CrossRef] [PubMed]

107. Higano, C.S. Side effects of androgen deprivation therapy: Monitoring and minimizing toxicity. Urology 2003, 61 (Suppl. 2), 32-38. [CrossRef] 
108. Sarnelli, A.; Belli, M.L.; Di Iorio, V.; Mezzenga, E.; Celli, M.; Severi, S.; Tardelli, E.; Nicolini, S.; Oboldi, D.; Uccelli, L.; et al. Dosimetry of ${ }^{177}$ Lu-PSMA-617 after mannitol infusion and glutamate tablet administration: Preliminary results of EUDRACT/RSO 2016-002732-32 IRST protocol. Molecules 2019, 24, 621. [CrossRef]

109. Von Eyben, F.E.; Baumann, G.S.; Baum, R.P. PSMA diagnostics and treatments of prostate cancer become mature. Clin. Transl. Imaging 2018, 6, 145-148. [CrossRef]

110. Langbein, T.; Chausse, G.; Baum, R.P. Salivary gland toxicity of PSMA radioligand therapy: Relevance and preventive strategies. J. Nucl. Med. 2018, 59, 1172-1173. [CrossRef]

111. Rathke, H.; Kratochwil, C.; Hohenberger, R.; Giesel, F.L.; Bruchertseifer, F.; Flechsig, P.; Morgenstern, A.; Hein, M.; Plinkert, P.; Haberkorn, U.; et al. Initial clinical experience performing sialendoscopy for salivary gland protection in patients undergoing ${ }^{225}$ Ac-PSMA-617 RLT. Eur. J. Nucl. Med. Mol. Imaging 2019, 46, 139-147. [CrossRef]

112. Baum, R.P.; Langbein, T.; Singh, A.; Shahinfar, M.; Schuchardt, C.; Volk, G.F.; Kulkarni, H. Injection of botulinum toxin for preventing salivary gland toxicity after PSMA radioligand therapy: An empirical proof of a promising concept. Nucl Med. Mol. Imaging 2018, 52, 80-81. [CrossRef] [PubMed]

113. Chatalic, K.L.; Heskamp, S.; Konijnenberg, M.; Molkenboer-Kuenen, J.D.; Franssen, G.M.; Clahsen-van Groningen, M.C.; Schottelius, M.; Wester, H.J.; van Weerden, W.M.; Boerman, O.C.; et al. Towards personalized treatment of prostate cancer: PSMA I\&T, a promising prostate-specific membrane antigen-targeted theranostic agent. Theranostics 2016, 6, 849-861. [PubMed]

114. Liu, T.; Liu, C.; Xu, X.; Liu, F.; Guo, X.; Li, N.; Wang, X.; Yang, J.; Yang, X.; Zhu, H.; et al. Preclinical evaluation and pilot clinical study of $\mathrm{Al}^{18} \mathrm{~F}-\mathrm{PSMA}-\mathrm{BCH}$ for prostate cancer imaging. J. Nucl. Med. 2019. [CrossRef] [PubMed]

115. Umbricht, C.A.; Benesova, M.; Schmid, R.M.; Turler, A.; Schibli, R.; van der Meulen, N.P.; Muller, C. ${ }^{44}$ Sc-PSMA-617 for radiotheragnostics in tandem with ${ }^{177}$ Lu-PSMA-617-preclinical investigations in comparison with ${ }^{68}$ Ga-PSMA-11 and ${ }^{68}$ Ga-PSMA-617. EJNMMI Res. 2017, 7, 9. [CrossRef] [PubMed]

116. Kratochwil, C.; Giesel, F.L.; Leotta, K.; Eder, M.; Hoppe-Tich, T.; Youssoufian, H.; Kopka, K.; Babich, J.W.; Haberkorn, U. PMPA for nephroprotection in PSMA-targeted radionuclide therapy of prostate cancer. J. Nucl. Med. 2015, 56, 293-298. [CrossRef] [PubMed]

117. Bacich, D.J.; Pinto, J.T.; Tong, W.P.; Heston, W.D. Cloning, expression, genomic localization, and enzymatic activities of the mouse homolog of prostate-specific membrane antigen/NAALADase/folate hydrolase. Mamm. Genome 2001, 12, 117-123. [CrossRef] [PubMed]

118. Simons, B.W.; Turtle, N.F.; Ulmert, D.H.; Abou, D.S.; Thorek, D.L.J. PSMA expression in the Hi-Myc model; extended utility of a representative model of prostate adenocarcinoma for biological insight and as a drug discovery tool. Prostate 2019, 79, 678-685. [CrossRef]

119. Tonnesmann, R.; Meyer, P.T.; Eder, M.; Baranski, A.C. $\left[{ }^{177}\right.$ Lu]Lu-PSMA-617 Salivary gland uptake characterized by quantitative in vitro autoradiography. Pharmaceuticals 2019, 12, 18. [CrossRef]

120. Rupp, N.J.; Umbricht, C.A.; Pizzuto, D.A.; Lenggenhager, D.; Topfer, A.; Muller, J.; Muhlematter, U.J.; Ferraro, D.A.; Messerli, M.; Morand, G.B.; et al. First clinico-pathological evidence of a non PSMA-related uptake mechanism for ${ }^{68}$ Ga-PSMA-11 in salivary glands. J. Nucl. Med. 2019. [CrossRef]

121. Roy, J.; Warner, B.; Basuli, F.; Williams, M.; Wong, K.; Ton, A.; Chiorini, J.; Choyke, P.; Lin, F.; Jagoda, E. Identifying an appropriate animal model to examine preservation of salivary function with PSMA targeted radiotherapies. J. Nucl. Med. 2018, 59 (Suppl. 1), 1255.

122. Rousseau, E.; Lau, J.; Kuo, H.T.; Zhang, Z.; Merkens, H.; Hundal-Jabal, N.; Colpo, N.; Lin, K.S.; Benard, F. Monosodium glutamate reduces ${ }^{68} \mathrm{Ga}$-PSMA-11 uptake in salivary glands and kidneys in a preclinical prostate cancer model. J. Nucl. Med. 2018, 59, 1865-1868. [CrossRef] [PubMed]

123. Jackson, P.F.; Cole, D.C.; Slusher, B.S.; Stetz, S.L.; Ross, L.E.; Donzanti, B.A.; Trainor, D.A. Design, synthesis, and biological activity of a potent inhibitor of the neuropeptidase $N$-acetylated $\alpha$-linked acidic dipeptidase. J. Med. Chem. 1996, 39, 619-622. [CrossRef] [PubMed]

124. Soeda, F.; Watabe, T.; Naka, S.; Liu, Y.; Horitsugi, G.; Neels, O.C.; Kopka, K.; Tatsumi, M.; Shimosegawa, E.; Giesel, F.L.; et al. Impact of ${ }^{18}$ F-PSMA-1007 uptake in prostate cancer using different peptide concentrations: Preclinical PET/CT study in mice. J. Nucl. Med. 2019. [CrossRef] [PubMed]

125. Wurzer, A.; Pollmann, J.; Schmidt, A.; Reich, D.; Wester, H.J.; Notni, J. Molar activity of Ga-68 labeled PSMA inhibitor conjugates determines PET imaging results. Mol. Pharm. 2018, 15, 4296-4302. [CrossRef] [PubMed] 
126. Majer, P.; Jancarik, A.; Krecmerova, M.; Tichy, T.; Tenora, L.; Wozniak, K.; Wu, Y.; Pommier, E.; Ferraris, D.; Rais, R.; et al. Discovery of orally available prodrugs of the glutamate carboxypeptidase II (GCPII) inhibitor 2-phosphonomethylpentanedioic acid (2-PMPA). J. Med. Chem. 2016, 59, 2810-2819. [CrossRef] [PubMed]

127. Matteucci, F.; Mezzenga, E.; Caroli, P.; Di Iorio, V.; Sarnelli, A.; Celli, M.; Fantini, L.; Moretti, A.; Galassi, R.; De Giorgi, U.; et al. Reduction of ${ }^{68}$ Ga-PSMA renal uptake with mannitol infusion: Preliminary results. Eur. J. Nucl. Med. Mol. Imaging 2017, 44, 2189-2194. [CrossRef] [PubMed]

(c) ( (C) 2019 by the authors. Licensee MDPI, Basel, Switzerland. This article is an open access article distributed under the terms and conditions of the Creative Commons Attribution (CC BY) license (http://creativecommons.org/licenses/by/4.0/). 